\title{
Disruption of the CNTF gene results in motor neuron degeneration
}

\author{
Yasuo Masu, Eckhard Wolf*, Bettina Holtmann, Michael Sendtner, \\ Gottfried Brem* \& Hans Thoenen
}

Abteilung Neurochemie, Max-Planck-Institut für Psychiatrie, Am Klopferspitz 18A, D-82152 Martinsried, Germany

* Institut für Molekulare Tierzucht, Ludwig-Maximilians-Universität, Veterinärstrasse 13, D-80539 München, Germany

CNTF is a cytosolic molecule expressed postnatally in myelinating Schwann cells and in a subpopulation of astrocytes. Although CNTF administration prevents lesion-mediated and genetically determined motor neuron degeneration, its physiological function remained elusive. Here it is reported that abolition of CNTF gene expression by homologous recombination results in a progressive atrophy and loss of motor neurons in adult mice, which is functionally reflected by a small but significant reduction in muscle strength.

CILIARY neurotrophic factor (CNTF) has many activities in vitro ${ }^{1.2}$, acting as a very potent survival factor for cultured parasympathetic', sympathetic', sensory' and spinal motor neurons $^{2-4}$, and hippocampal neurons ${ }^{5}$. Moreover, CNTF is a cholinergic differentiation factor (increasing choline acetyltransferase (ChAT) and reducing tyrosine hydroxylase (TH) levels) for primary cultures of rat sympathetic neurons ${ }^{6}$. It also promotes the survival of oligodendrocytes ${ }^{7}$ and the differentiation of O-2A glial precursor cells into type-II astrocytes in vitro ${ }^{8}$.

Furthermore, the local administration of CNTF in vivo prevents the degeneration of facial nerve motor neurons after axotomy in the early postnatal period ${ }^{9}$ and also markedly interferes with the degenerative changes in progressive motor neuronopathy $(\mathrm{pmn})$ mutant mice ${ }^{10}$. Although these observations provide promising perspectives for the therapeutic use of CNTF, the physiological function of CNTF remains elusive. CNTF is expressed postnatally in myelinating Schwann cells and in a subpopulation of astrocytes ${ }^{11}$. The structure of the molecule (lack of leader sequence $)^{12,13}$, its immunohistochemical localization in the cytosol ${ }^{11,14}$ and the absence of release of substantial quantities of CNTF into the culture medium of primary cultures of astrocytes $^{15}$ and transfected Cos or HeLa cells ${ }^{12,13}$ characterize CNTF as a typical non-secreted cytosolic molecule. These characteristics strongly suggest that CNTF is not a physiological survival factor for motor neurons during embryonic development, because the period of naturally occurring motor neuron cell death in mice and rats is over at birth ${ }^{16}$. But the cytosolic localization of CNTF and the evidence against its secretion along the classic endoplasmic reticulum (ER)-Golgi pathway does not exclude the possibility of an unconventional, regulated release, for example, as suggested for basic fibroblast growth factor $(\mathrm{FGF})^{17,18}$. The localization of CNTF in myelinating Schwann cells and its relatively high quantities in the cytosol ${ }^{11.14 .19}$ in comparison to its very high potency as a neurotrophic factor ${ }^{1,3}$ suggests that only a very small proportion of the cytosolic CNTF needs to reach the axons of the responsive neurons and that CNTF might have a maintenance function in postnatal neurons, in particular motor neurons. The site of synthesis and expected site of action of CNTF, together with its postnatal expression, invited an evaluation of its function by elimination of its expression by gene targeting.

Here we report on the abolition of CNTF expression by homologous recombination resulting in the disappearance both of CNTF protein and of the corresponding biological activity in the CNTF null (CNTF - /-) mutant mice. We concentrated on the evaluation of the physiological function of CNTF for motor neurons. As anticipated, the inactivation of CNTF expression did not affect the number of motor neurons during embryonic development. Also during the first postnatal weeks neither functional nor morphological changes were apparent. But with increasing age, spinal motor neurons exhibited progressive atrophy and finally degeneration, functionally reflected by a small but statistically significant reduction in muscle strength.

\section{Inactivation of the CNTF gene}

The CNTF gene was disrupted according to established methods ${ }^{20.21}$. The targeting vector used contained 9.5 kilobases (kb) of homologous CNTF genomic DNA in which the protein coding region of exon one was disrupted by insertion of a $1.1 \mathrm{~kb}$ MC 1 neo ${ }^{R}$ expression cassette without a poly $(\mathrm{A})^{+}$signal. The $n e o^{\mathrm{R}}$ protein coding sequence was followed by several translation stop codons to prevent any translational read-through (Fig. 1a).

D3 embryonic stem cells $\left(2 \times 10^{7}\right)$ (ref. 22) were transfected with the linearized targeting vector by electroporation. The cells were selected in medium containing $380 \mu \mathrm{g} \mathrm{ml}^{-1} \mathrm{G} 418$ (positive selection) and $2 \mu \mathrm{M}$ of gancyclovir (negative selection). Of the 690 G418-resistant clones initially screened by polymerase chain reaction (PCR), 4 had the expected $0.6 \mathrm{~kb}$ DNA fragment with a frequency of 1 in 170 resistant clones. The results obtained by the PCR procedures were verified by Southern blot analysis in the corresponding clones.

TABLE 1 Number of facial motor neurons in controls and CNTF -/mice

\begin{tabular}{ccc}
\hline Age & CNTF $+/+$ and $+/-$ & \multicolumn{1}{c}{ CNTF $-/-$} \\
4 weeks & $1,998 \pm 131(n=6)$ & $2,033 \pm 90 \quad(n=7)$ \\
28 weeks & $2,092 \pm 106(n=7)$ & $1,620 \pm 73^{*}(n=8)$ \\
\hline
\end{tabular}

The brain stems from 4 - and 28-week-old CNTF - $/$ - mice were perfused with $4 \%$ formaldehyde and prepared for paraffin serial sections $(7 \mu \mathrm{m})$ as described ${ }^{9.10}$. Briefly, the sections were Nissl-stained, and nucleoli of facial motor neurons were determined in every fifth sectlon. Age-matched CNTF $+/+$ and $+/-$ mice (whose levels of CNTF protein and bioactivity were indistinguishable in sciatic nerve extracts (data not shown) were used as controls. The diameters of the nucleoli were measured at high magnification $(\times 1,000)$. Average diameter of nucleoli in each group: 4-week-old $+/ t$ and $+/-$ mice, $3.7 \pm 0.7 \mu \mathrm{m}$ (mean \pm s.d. for 54 determinations); 4 -week-old $-/-$ mice, $3.6 \pm 0.4 \mu \mathrm{m}$ (mean \pm s.d. from 55 determinations); 28 -week-old $+/+$ and $+/-$ mice, $3.3 \pm 0.4 \mu \mathrm{m}$ (mean \pm s.d. from 54 determinations); 28 -week-old $-/-$ mice, $3.5 \pm 0.4 \mu \mathrm{m}$ (mean \pm s.d. from 52 determinations). The counts of facial nucleoli of each animal (mean from independently counted left and right side) were corrected according to ref. 33. Values shown are mean \pm s.e.m. of each group. Statistical significance of the difference between (corrected) motor neuron number in 28-week-old CNTF - / mice and controls was tested by Student's t-test.

* The two groups are different at the 0.005 level $(P=0.002)$. 


\section{ARTICLES}

$a$
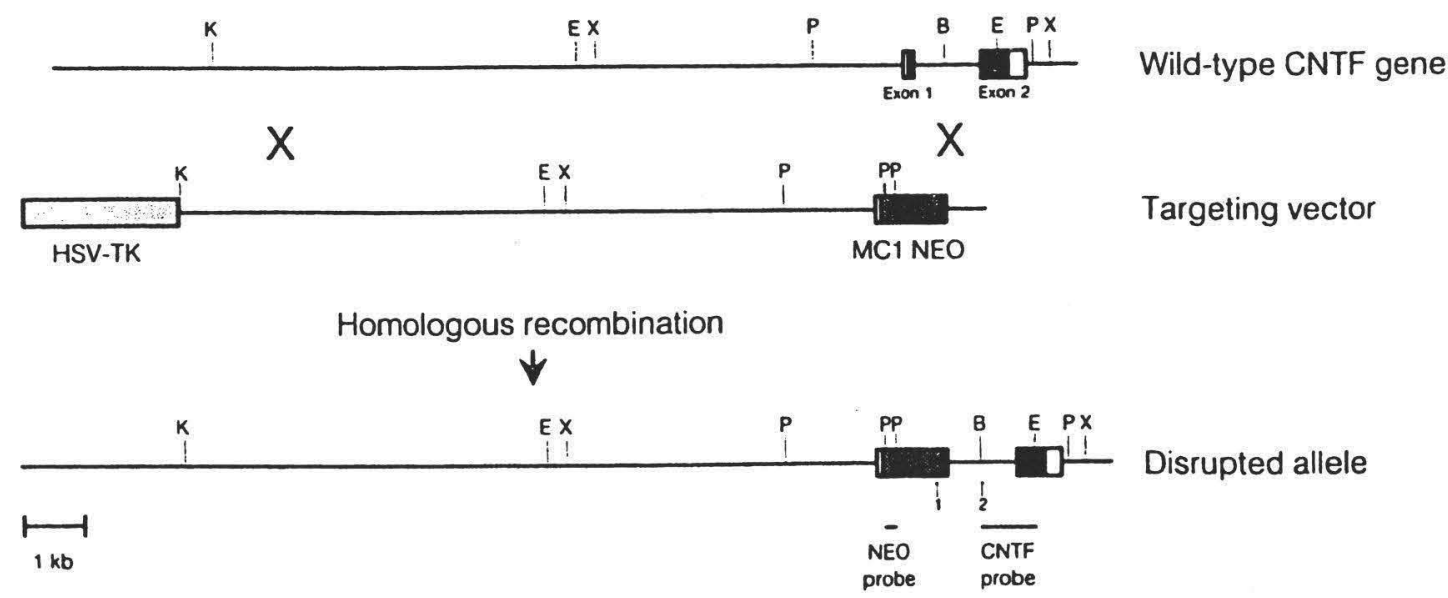

$b$

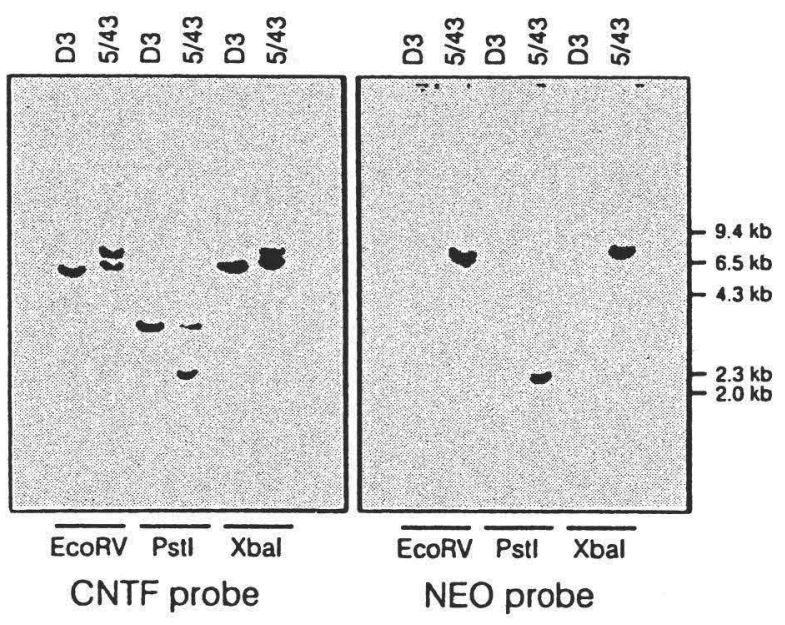

$c$

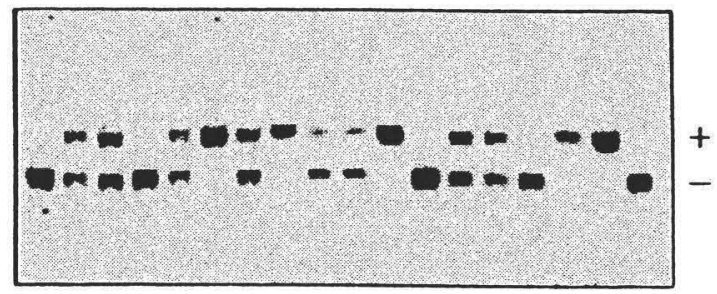

FIG. 1 Disruption of the CNTF gene in mouse embryonic stem (ES) cells. a, Targeting vector. Top line, Normal genomic structure of the mouse CNTF gene. Exons 1 and 2 are shown as boxes, black boxes represent coding regions. Middle line, Targeting replacement vector used to disrupt the endogenous CNTF gene. The MC1 neo-cassette lacking a polyadenylation signal was inserted into the Nhel site 63 base pairs (bp) downstream of the initiator codon. Homologous recombination will generate a fusion gene of neomycin and the endogenous CNTF $3^{\prime}$ untranslated region. Negative selection using gancyclovir against HSV thymidine kinase gene expression did not lead to an enrichment of targeted clones in our experiment PCR primers 1 ( $5^{\circ}$-CCTCTATCGCCTTCTTGAC) and 2 (5'-AAACAAGCCCAGAACTGTGG) were used to identify targeting events in neo ${ }^{R}$ ES cells. The bottom line represents the structure of the mutated CNTF gene. Restriction enzyme abbreviations: K, Kpnl; E, EcoRV; X. Xbal; P, Pstl; B, BgIII. b, Southern blot analysis of ES cell clone 5/43 containing a targeted disruption of the CNTF gene. DNA samples from D3 ES cell clone 5/43 were digested with EcoRV, Pstl or Xbal and analysed with two different probes. Left, CNTF probe, 850 bp Bg川IECoRV fragment of the CNTF gene not present in the targeting vector DNA; right, Neo probe, 200 bp Pstl fragment of the neo gene. Molecular size markers are shown to the right. $c$, Southern blot analysis of DNA from offspring from CNTF $+/-\times$ CNTF $+/-$ mating. DNA was extracted from tail-tips, digested with Pstl and analysed with the CNTF probe as described in $b$. The mutated CNTF gene resulted in a shorter fragment as shown in $b$. The position of the wild-type and mutated alleles are indicated on the right.

METHODS. a, The CNTF targeting vector was constructed by subcloning a $9.5 \mathrm{~kb} \mathrm{Kpnl-Bglll}$ fragment containing exon 1 of murine genomic CNTF DNA into pBluescript KS (Stratagene). A $1.1 \mathrm{~kb}$ Sall-Xhol fragment of the MC1 neo cassette (without a poly(A) ${ }^{+}$signal) was inserted into the Nhel site which was converted to a Xhol site. An HSV-TK cassette was then inserted at the Kpnl site. D3 ES cells were cultured (in DMEM with $15 \%$ FCS and $60 \%$ Buffalo rat liver cell conditioned Glasgow medium) on embryonic fibroblast feeder layers derived from neomycin-resistant transgenic mice. ES cells $\left(2 \times 10^{7}\right)$ in PBS, divided equally into five cuvettes, were electroporated with $125 \mu \mathrm{g}$ Notl-linearized targeting vector DNA at $240 \mathrm{~V},<500 \mu \mathrm{F}$ (Biorad Gene Pulser). Cells were selected in medium containing $380 \mu \mathrm{g} \mathrm{ml} \mathbf{m}^{-1} \mathrm{G} 418$ and $2 \mu \mathrm{M}$ gancyclovir for 10 14 days. The resistant clones were picked and placed into 48 -well plates with feeder layers. Cells were trypsinized the next day, and a 40 cycle PCR amplification (40 s at $94^{\circ} \mathrm{C}, 1 \mathrm{~min}$ at $55^{\circ} \mathrm{C}$ and $3 \mathrm{~min}$ at $70^{\circ} \mathrm{C}$ ) was performed on pools (each containing about $10^{4}$ cells) of 10 clones to screen for homologous recombinant clones. PCR primers 1 and 2 would be expected to give rise to a 600 bp product only when the vector was integrated correctly into the CNTF locus. Individual targeted clones from positive pools were identified by PCR (data not shown). Correct homologous recombination was confirmed by Southern blot analysis. b. The positive ES cell clone $(5 / 43)$ ad D3 ES cells were expanded and DNA isolated ${ }^{36}$. DNA $(10 \mu \mathrm{g})$ was digested with restriction enzymes as indicated, electrophoresed in $0.6 \%$ agarose gels in $1 \times$ TBE ( $89 \mathrm{mM}$ Tris borate, $1 \mathrm{mM}$ EDTA) buffer, and blotted under alkali conditions to Hybond $\mathrm{N}+$ (Amersham) membranes. Prehybridization was done for $3 \mathrm{~h}$ at $65^{\circ} \mathrm{C}$ in $1 \mathrm{M} \mathrm{NaCl}, 1 \%$ SDS, $1 \mathrm{mM}$ EDTA and $10 \mathrm{mM}$ Tris- $\mathrm{HCl}$ containing $10 \%$ dextran sulphate. Hybridization was in the same buffer using ${ }^{32} \mathrm{P}$-labelled probe $\left(10 \times 10^{6}\right.$ c.p.m. $\left.\mathrm{ml}^{-1}\right)$. The membranes were washed for $10 \mathrm{~min}$ at room temperature in $2 \times$ SSC, twice for $30 \mathrm{~min}$ at $65^{\circ} \mathrm{C}$ in $0.1 \times \mathrm{SSC}, 1 \%$ SDS and then exposed to $\mathrm{X}$-ray film (Kodak X-Omat). 
For blastocyst injection we selected clone $5 / 43$ which showed correct integration of the targeting vector at the CNTF locus (Southern blot analysis, Fig. 1b). Moreover, this clone showed a virtually exclusive diploid (40 chromosomes) chromosomal pattern (data not shown). Chimaeric mice were generated by microinjection of $5 / 43$ cells into 3.5 -day-old blastocysts from C57BL/6 mice (non-agouti). As the D3 embryonic stem (ES) cell line is derived from the $129 / \mathrm{SV}$ strain (agouti), chimaeric mice were identified by coat colour. The ES cell contribution as estimated by agouti pigmentation averaged $80 \%$ for the whole experimental series. Male chimaeric mice were tested for germline transmission of the mutated CNTF gene. From 12 males analysed, 2 showed germ-line transmission as demonstrated by the production of agouti offspring (for details, see ref. 23). $\mathrm{CNTF}+/-$ heterozygotes were mated and 98 offspring were evaluated by Southern blot analysis. The ratio of CNTF $+/+,+/-$ and $-/-$ in the offspring was about $1: 2: 1$ following mendelian rules (Fig. Ic).

\section{Effectiveness of gene targeting}

Western blot analysis of sciatic nerve extracts demonstrated that the immunoreactivity detected in control mice by an IgG fraction of rabbit anti-CNTF antiserum ${ }^{19}$ was absent in CNTF $-/$ - mice (Fig. 2a). Accordingly, no CNTF-assignable survival activity was present in the corresponding sciatic nerve extracts, as evaluated with embryonic chick ciliary neurons in culture (Fig. 2b). Even in the presence of $1,000 \mathrm{ng}$ protein from sciatic nerve extracts of CNTF --/- mice, no survival of ciliary neurons was detectable, whereas $100 \mathrm{ng}$ sciatic protein extract from CNTF $+j+$ mice already showed maximal responses. Moreover, the ciliary neuronal survival activity of CNTF $+i+$ sciatic nerves could be completely blocked by an IgG fraction of a blocking CNTF antiserum. Thus the protein product of the CNTF gene was absent in CNTF $-/-$ mice as expected from the genomic findings.

\section{CNTF inactivation on spinal cord motor neurons}

The morphometric analysis of lumbar spinal cord motor neurons (Fig. 3a) demonstrated no detectable difference between 4-weekold CNTF $-/-$ and $\mathrm{CNTF}+/+$ mice. Moreover, the number of facial motor neurons was not significantly different $(P=0.8)$, as shown by cell counting in serial sections of the brain stem (Table 1). This indicates that the absence of CNTF protein does not influence the development of motor neurons during the first postnatal weeks. But in 8-week-old animals, lumbar motor neuron cell bodies were smaller, and the nuclei swollen (Fig. 3c) resulting in an average increase in the ratio between nuclear and cytoplasmic areas of about $40 \%$ (Fig. $3 a$ ). Both the differences between cell sizes and the ratios of nuclear and cytoplasmic areas were statistically significant $(P<0.001)$. In 14 -week-old animals, both the lumbar motor neuron cell area and the nuclear area were smaller in CNTF $-/-$ mice than in CNTF $+/+$ mice, resulting in an apparent 'normalization' of the ratio between the nuclear and cytoplasmic areas of these cells (Fig. $3 a$ ).

In CNTF - / - mice some motor neurons showed a distinct reduction of the Nissl structure (Fig. $3 c$ ), and others were surrounded by cells with small nuclei resembling activated glial cells (Fig. $3 d, e$ ). Similar morphological changes became apparent in sections of facial nuclei, which were prepared by different fixation, embedding and staining procedures (Fig. $3 h-k$ ). These morphological changes were already detectable in 8-week-old CNTF $-/-$ animals (Fig. $3 d$ ) and became more pronounced in 24week-old animals (Fig. $3 e, f$ ) compared to controls (Fig. $3 g$ ). In 28 -week-old animals the number of facial motor neurons was reduced by $22 \%$ compared to age-matched controls $(P=0.002)$ (Table 1), demonstrating the progression of the atrophic to degenerative changes, resulting finally in motor neuron cell death. The facial nucleus was chosen for counting motor neuron cell numbers as this clearly delineated structure in the brain stem does not contain interneurons, and therefore permits a more reliable quantification than the analysis of the ventrolateral column of the spinal cord.

In parallel with the degenerative changes and loss of motor neurons, there was a small but statistically significant $(P=0.034)$ reduction in muscle strength in 28 -week-old animals (Table 2 ). The progressive atrophic and degenerative changes in lumbar spinal motor neurons were accompanied by an increased number

$a$

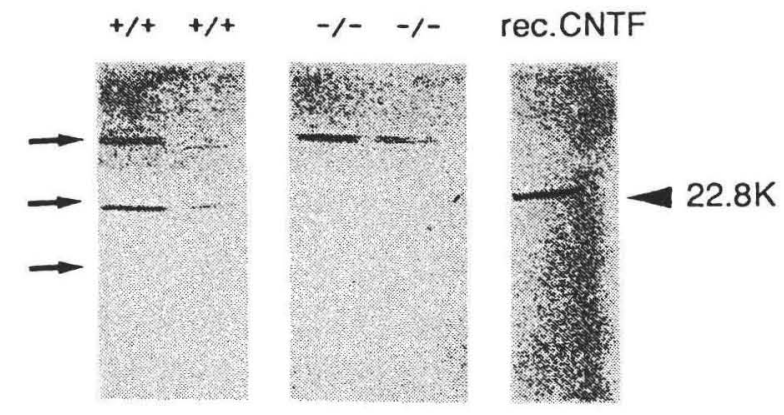

b

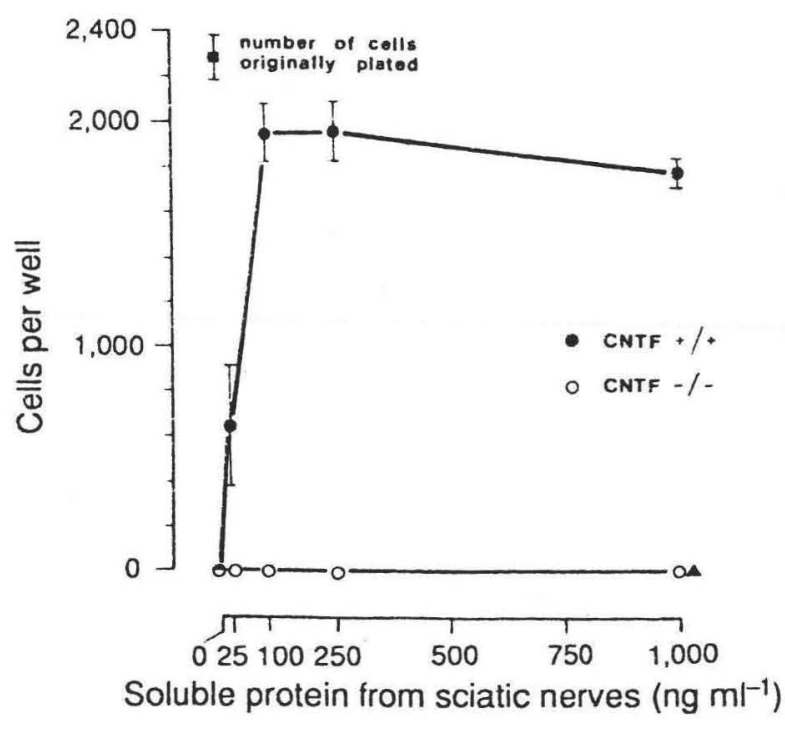

FIG. 2 Analysis of CNTF protein expression and biological activity in CNTF - / - mice. $a$, Western blot analysis of sciatic nerve extracts. Sciatic nerves from adult CNTF $+/+$ and CNTF $-1-$ mice were prepared, homogenized and ultracentrifuged as described ${ }^{19}$. Protein ( $30 \mu \mathrm{g}$ per lane) was electrophoresed. The arrows at the left indicate the position of molecular mass markers (ovalbumin, 45K; trypsinogen, $24 \mathrm{~K}$; lysozyme, 14.3K). CNTF immunoreactive bands were detected by a rabbit antiserum $(1: 1,000)$ against rat CNTF. CNTF immunoreactivity is absent in extracts from CNTF $-/-$ mice whereas a clear band of the expected size $(22.8 \mathrm{~K})$ is detectable in CNTF $+/+$ nerve extracts. The doublet band of about $44 \mathrm{~K}$ was also recognized in the absence of the primary antiserum and most probably represents immunoglobulin heavy chains recognized by the secondary antiserum. $b$, CNTF-bioactivity in nerve extracts from CNTF $+/+$ and CNTF - / - mice. Embryonic (day 8) chick ciliary neurons were prepared and cultured (for $24 \mathrm{~h}$ ) as described $^{19}$. Protein extracts from sciatic nerves were added at the concentrations shown. Each determination was done at least in duplicates. The survival activity present in $1 \mathrm{mg}$ of nerve extracts from CNTF $+1+$ mice could be completely blocked by the addition of $6 \mu \mathrm{g} \mathrm{ml} l^{-1}$ of an igG fraction of a blocking CNTF antiserum ${ }^{10}$. demonstrating that the survival activity of sciatic nerve extracts in this assay stems exclusively from CNTF. 


\section{ARTICLES}

of activated microglial cells (Fig. 4), as visualized by horseradish peroxidase conjugates of the B4 isolectin from Griffonia simplicifolia ${ }^{24.25}$. The ventrolateral region of the spinal cord of CNTF $-/-$ mice contained more lectin-labelled microglial cells in comparison to the corresponding regions of $\mathrm{CNTF}+/+$ mice.

$a$

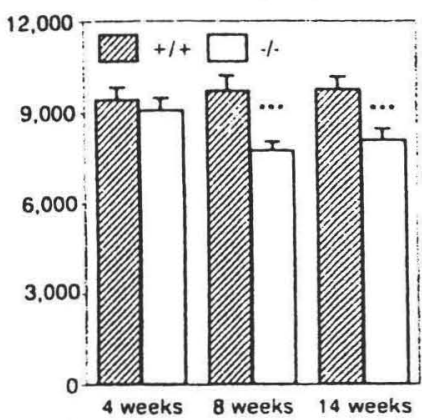

Nucleus/cytoplasm ratio (\%)

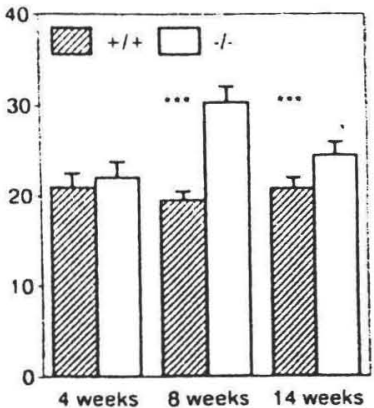

Although the intensity of the microglial staining in CNTF - /mice varied between experiments (Fig. $4 d, f$ ), there was a distinct difference compared to $\mathrm{CNTF}+/+$ mice in all experiments. In addition to the increase in lectin binding, a significant proportion of the microglial cells in spinal cords of CNTF $-/$ - mice were closely associated with motor neurons and showed a reduced branching of their cytoplasmic processes, exhibiting features of activated microglia ${ }^{25}$ (Fig. $4 b, d, f$ ).

\section{Discussion}

These investigations evaluated whether CNTF is involved in the physiological maintenance of structure and function of motor neurons. It was already known that CNTF is a cytosolic molecule whose expression is restricted to myelinating Schwann cells and a subpopulation of astrocytes ${ }^{11,14}$. The restricted expression of CNTF both in the periphery and in the CNS is in distinct contrast to the very broad spectrum of its biological actions in vitro ${ }^{1-8}$. Among these, the effective support of motor neurons in vitro and in vivo was of particular interest. The levels of CNTF protein in the sciatic nerve are about 10,000 times
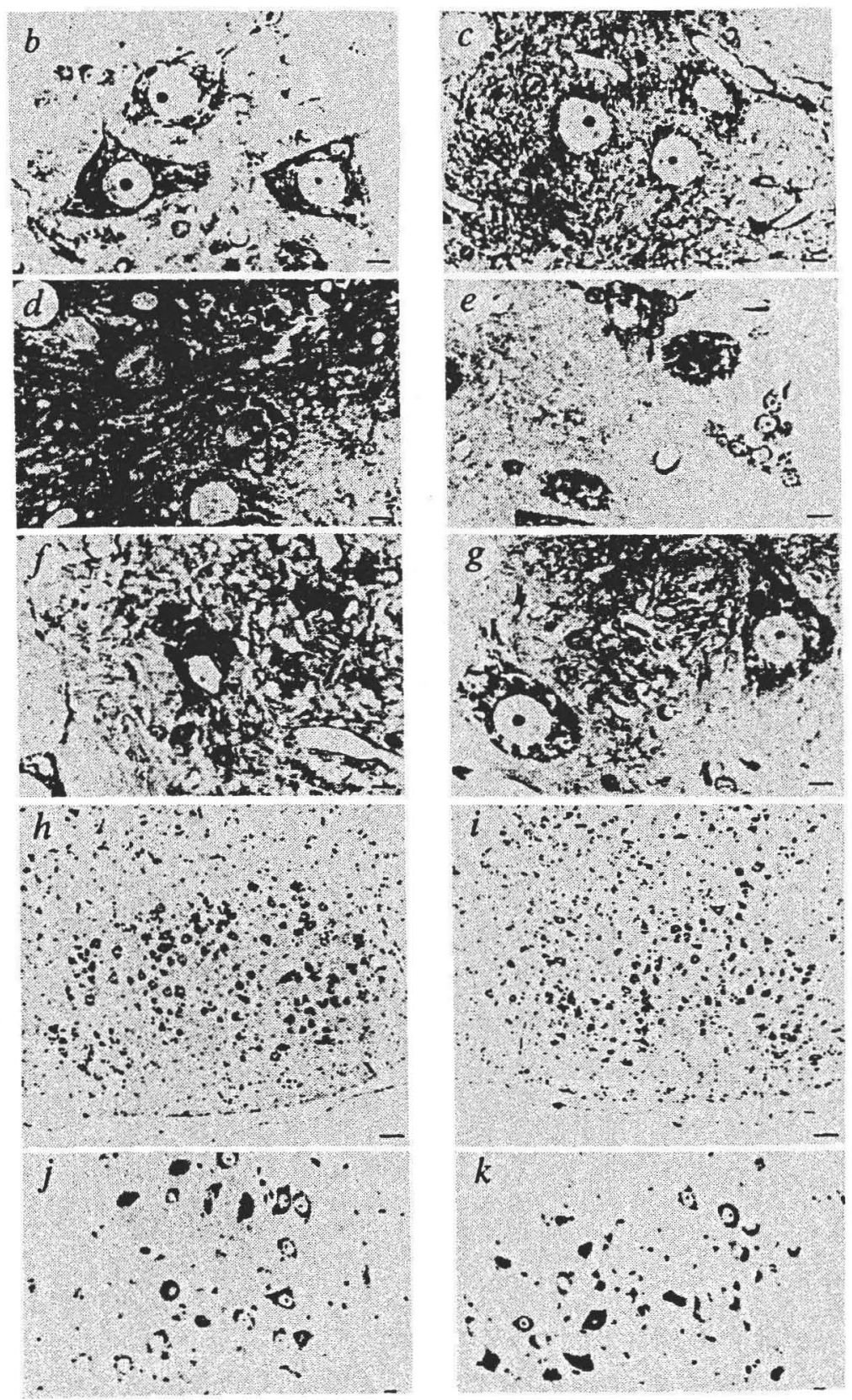

FIG. 3 Analysis of motor neuron cell size and structure in CNTF - / - mice. a, Morphometry of lumbar motor neuron cell size and determination of the nucleus/cell ratio. $b$, Motor neurons in CNTF $+/+$ mice ( 8 weeks old). c, Motor neurons in CNTF $-/-$ mice ( 8 weeks old). $d, e, f$, Ventrolateral spinal cord region of 8-week-old (d) and 24-weekold $(e, f)$ CNTF $-1-$ mice showing motor neurons with reactive glial cells (arrows) and degenerating neurons (arrowhead). g, Lumbar motor neurons from a 24-weekold CNTF $+/-$ control mouse. $h-k$, Facial motor neurons in 6-month-old CNTF $+/-(h, j)$ and $-1-$ mice $(i, k)$ at low $(h, i)$ and high $(j, k)$ magnification. Brain stems were prepared for Nissl stained paraffin sections as described in legend to Table 1. Scale bars in b-g, j, $k, 10 \mu \mathrm{m}$; in $h, i$, $50 \mu \mathrm{m}$.

METHODS. CNTF $-1-$ and CNTF $+1+$ mice of different ages were perfused first with PBS containing $0.002 \%$ butanilicain and then with $4 \%$ paraformaldehyde/ $1 \%$ glutaraldehyde. The lumbar spinal cords (level L3-L5) were dissected and postfixed with $2 \%$ glutaraldehyde in a sodium-cacodylate buffer for at least three days at $4^{\circ} \mathrm{C}$ (ref. 37). After rinsing in PBS containing 3.4\% sucrose, the tissues were incubated with osmium tetroxide $(1 \%)$ in a $2 \%$ potassium dichromate solution and processed for Epon embedding according to standard procedures ${ }^{38}$. Semi-thin sections $(1 \mu \mathrm{m})$ were prepared and stained with toluidine blue. Sections were analysed with a Zeiss Axiophot microscope (magnification $\times 1,000$ ) and mor phometry was done using a Bioscan Optimas picture analysis hard-and software coupled to the microscope. Total cell and nuclear areas from motor neurons with typical Nissl structure and a clearly identifiable nucleolus were analysed from 10 sections per animal. These sections were at least $10 \mu \mathrm{m}$ apart from each other to avoid double analysis of the same cells. At least 160 motor neurons were analysed for each age group in CNTF $+/+$ animals, and more than 210 motor neurons were analysed for each age group in CNTF $-/-$ mice. Statistical analysis. Analysis of variance was done on cell and nuclear area data from CNTF $+/+$ and CNTF $-1-$ mice taking into account variances due to sections and individual animals. The General Linear Models (GLM) procedure (SAS Institute Inc.) $)^{35}$ was used to calculate least squares means (LSM) and standard errors (s.e.). LSM were compared within age class using Student's t-test. Data shown represent LSM and s.e. for cell area and nuclear area/cytoplasmic area ratio of alpha motor neurons from CNTF $+/+$ and CNTF $-/-$ mice at different ages as indicated. ${ }^{* * *}$, Statistically significant differences $(P<0.001)$. 
higher than those of the secretory nerve growth factor (NGF) ${ }^{19}$. But because of its cytosolic location, the question arose whether CNTF becomes available to the responsive ncurons under normal conditions and whether therefore CNTF has a physiological function at all. The quantities of CNTF released into the medium by primary cultures of Schwann cells and astrocytes are very small and are within the limits of the release of cytosolic molecules by normal cell death under the given culture conditions ${ }^{15}$. Therefore, it would be difficult to detect additional small quantities of CNTF released by a non-conventional, regulated mechanism as has been demonstrated, for example for basic $\mathrm{FGF}^{17,18}$. Moreover, even if such a mechanism could be identified and characterized in vitro, would the observations made be representative for the situation in vivo where Schwann cells express much higher CNTF levels than Schwann cells in culture and, as myelinating cells, are in a distinctly different structural and functional situation? Thus, it was essential to evaluate the potential physiological function of CNTF in vivo. Because the spatial relationship between the CNTF-producing Schwann cells and the responsive neurons precluded the use of antibodies, the abolition of CNTF production by homologous recombination was the chosen method. The structure and function of motor neurons in the early postnatal phase would be expected to be normal given that the expression of CNTF starts in the first postnatal week and does not reach adult levels before the 4 th $^{\text {week }}{ }^{2,13}$. Indeed, no changes in the morphology or function were detectable in 4-week-old animals. But subsequently there was a gradually increasing atrophy of spinal motor neurons which first became apparent at postnatal week 8 . Furthermore, in the 28week-old animals, a statistically $(P=0.002)$ significant reduction by $22 \%$ in motor neuron cell numbers became apparent (Table 1) in the well delineated facial nucleus. The slowly progressing atrophy and final degeneration of motor neurons was accompanied by an increasing number of reactive microglial cells in the vicinity of the motor neurons. In contrast, increased GFAP staining in reactive astrocytes, which is a characteristic of acutely degenerating motor neurons ${ }^{26}$, could not be observed. This is reminiscent of the absence of enhanced GFAP reactivity in the genetically determined progressive degeneration of motor neurons in $\operatorname{dogs}^{27}$. Even at 22 weeks, when the first signs of motor neuron degeneration became apparent, there was still no evidence of an impaired motor neuron function (Table 2). But at 28 weeks a small but statistically significant $(P=0.034)$ reduction in muscle strength (Table 2) became apparent. Major differences were, in any case, not expected because in many neuronal systems a high proportion of neurons have to degenerate before
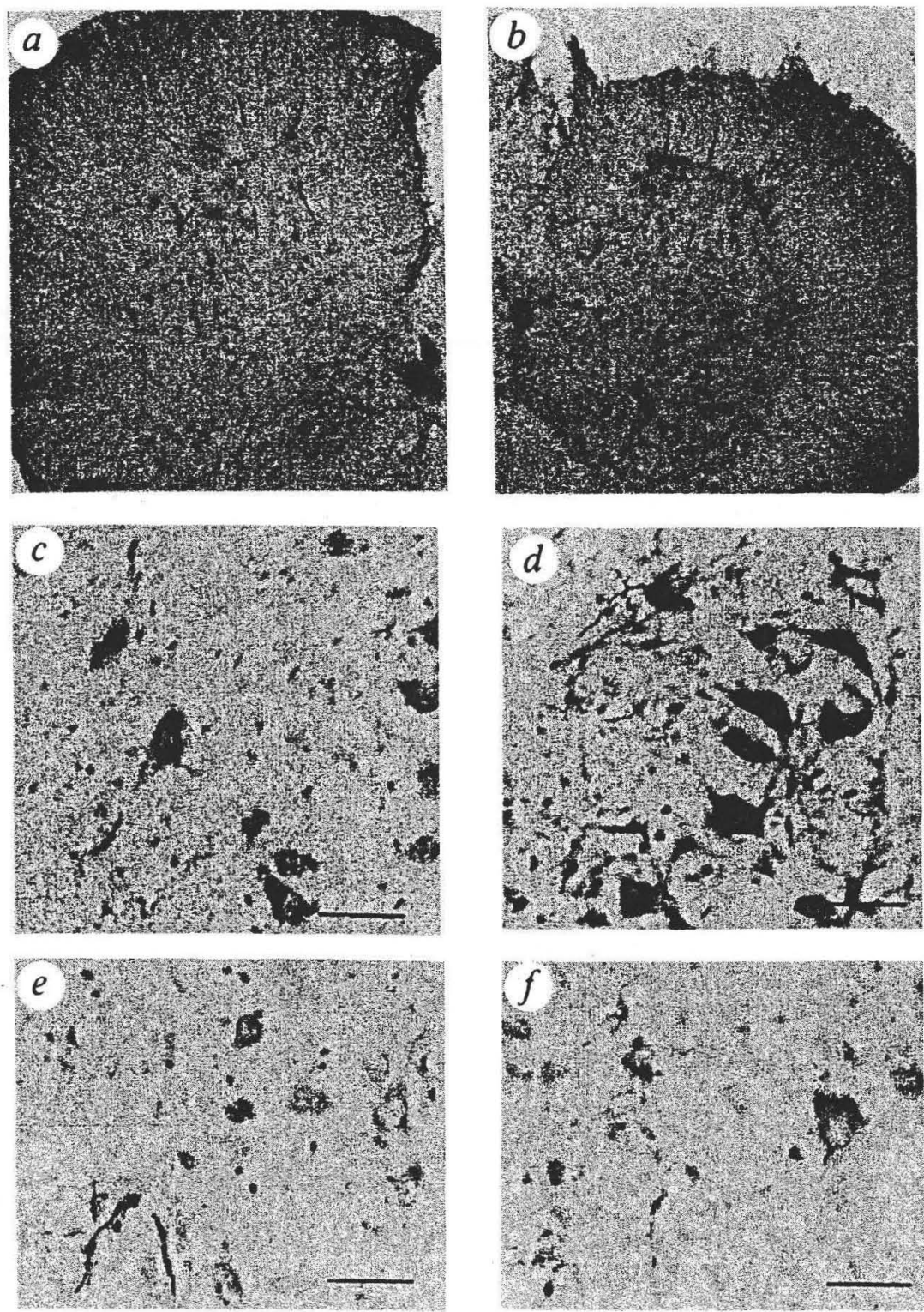

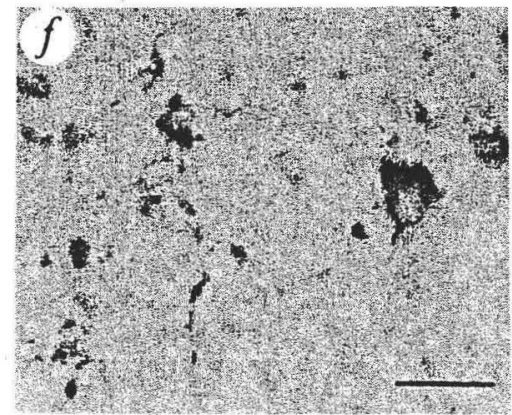

FIG. 4 Microglia reaction in the anterior horn of the upper lumbar spinal cord of CNTF - / mice. $a, b, e, f, 24$-week-old $\mathrm{CNTF}+/+$ mice $(a, e)$ and CNTF $-/-$ mice $(b, f)$ at low $(a, b)$ and high magnification $(e, f)$. The anterior horn region of the spinal cord in $a$ and $b$ is arrowed. Insert in e shows the appearance of a microglial cell within the anterior horn region from the same CNTF $+/+$ animal. c, d, 8-week-old control $($ CNTF $+/+)(c)$ and CNTF $-/-$ mouse $(d)$. Each pair of figures $(a / b, c / d, e / f)$ was derived from independent experiments and the processing for each pair of sections was identical. After preparation of vibratome sections $(40 \mu \mathrm{m})$ of paraformaldehyde (4\%) fixed upper lumbar spinal cords, microglia was identified by lectin binding (Griffonia simplicifolia (GSA-B4) coupled to horseradish peroxidase (Sigma, L539)) as described $^{24}$. Diaminobenzidine was used to visualize microglia, sections were counterstained with cresyl violet. The specificity of the lectin Griffonia simplicifolia for microglia is not absolute, it also stains endothelial cells and basal membranes. Scale bars, $50 \mu \mathrm{m}$. 


\section{ARTICLES}

TABLE 2 Forelimb grip strength of male CNTF $+/+$ and CNTF - /mice at different ages

\begin{tabular}{crrrrr}
\hline \multicolumn{6}{c}{$\begin{array}{c}\text { Mean grip strength (in Newtons) } \\
\text { CNTF }+/+\end{array}$} \\
Age & $n$ & & $n$ & CNTF $-/-$ \\
8 Weeks & 7 & $1.149 \pm 0.013$ & 3 & $1.117 \pm 0.020$ & $P=0.187$ \\
22 Weeks & 10 & $1.288 \pm 0.012$ & 8 & $1.314 \pm 0.013$ & $P=0.131$ \\
28 Weeks & 5 & $1.203 \pm 0.040$ & 13 & $1.107 \pm 0.020$ & $P=0.034$ \\
\hline
\end{tabular}

Forelimb grip strength (in Newtons) was determined in male CNTF $+/+$ and $-/-$ mice using the automated grip strength meter described in ref. 34. Briefly, after the animals were placed on a platform and allowed to grasp a triangular ring, they were pulled away until the grip was broken. Grip strength was determined with a computerized electronic pull strain gauge (Columbus Instruments) which was directly fitted to the grasping ring. Seven measurements were taken from each animal within a minute. The grip strength was measured blindly, the person measuring the strength did not know whether the mice were CNTF $+/+$ or $-/-$. Data were analysed by analysis of variance taking into account the variation of data within each animal. The GLM procedure (SAS Institute, Inc.) was used to calculate the least-squares means (LSM) and standard errors (s.e.) $)^{35}$ shown for each group. Student's t-test was used to compare LSM of CNTF $+/+$ and CNTF $-/$ - mice within the same age class. Significance of differences ( $P$ values) between groups are shown in the last column.

signs of functional deficiency become apparent. For example, in patients suffering from amyotrophic lateral sclerosis, accumulating evidence suggests that the first clinical symptoms usually do not occur before about $50 \%$ of the spinal motor neurons are $\operatorname{lost}^{28}$. This would agree with the situation in CNTF $-/-$ mice. Future experiments with older CNTF $-/-$ animals will show whether the absence of the CNTF supporting function will lead to further degenerative changes and further reduction in muscle strength leading finally to a clearly detectable impairment of gross motor neuron function. In this context, it will be particularly interesting to see whether compensatory mechanisms come into play, for example the reactive production of BDNF by Schwann cells, provided a sufficiently high level of axon degeneration has been reached, and whether a similar reactive production of BDNF would be obtained as after nerve lesion ${ }^{29}$.

The targeting experiments show that CNTF plays an essential role in the maintenance of motor neuron function in the postnatal period. But they do not reveal how CNTF is transferred from Schwann cells to its motor neuron targets. This might occur via regulated membrane transfer by a specific unconventional mechanism or after uncontrolled release from the cytosol resulting from incidental discontinuity of the plasma membrane. The

Received 17 February, accepted 22 July 1993.

1. Barbin, G.. Manthorpe. M. \& Varon. S. J. Neurochem. 43, 1468-1478 (1984).

2. Sendtner, M., Arakawa, Y., Stöckli, K. A., Kreutzberg. G. W. \& Thoenen, H. J. Cell Sci. 15 (suppl.), 103-109 (1991).

3. Arakawa, Y.. Sendtner, M. \& Thoenen, H. J. Neurosci. 10, 3507-3515 (1990).

4. Magal, E., Burnham, P. \& Varon, S. Devl Brain Res. 63, 141-150 (1991).

5. Ip. N. Y. et al. J. Neurosci. 11, 3124-3134 (1991).

6. Saadat, S., Sendtner, M. \& Rohrer, H. J. Cell Biol. 108, 1807-1816 (1989).

7. Louis, J. C., Magal, E., Takayama, S. \& Varon, S. Science 259, 689-692 (1993)

8. Lillien. L. E. \& Raff, M. C. Neuron 5, 111-119 (1990).

9. Sendtner. M., Kreutzberg. G. W. \& Thoenen, H. Nature 345, 440-441 (1990).

10. Sendtner, M. et al. Nature 358, 502-504 (1992).

11. Stöckli, K. A. et al. J. Cell Biol. 115, 447-459 (1991).

12. Lin, L.F. H. et al. Science 246, 1023-1025 (1989).

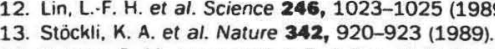

14. Dobrea, G. M., Unnerstall, J. R. \& Rao, M. S. Devi Brain Res. 66, 209-219 (1992)

14. Dobrea, G. M., Unnerstall, J. R. \& Rao, M. S. Devl Brain Res. 66, 209-219 (1992).
15. Lillien, L. E., Sendtner, M., Rohrer, H., Hughes, S. M. \& Raff, M. C. Neuron 1, 485-494 (1988).

16. Oppenheim. R. W. J. comp. Neurol. 246, 281-286 (1986).

17. Mignatti, P., Morimoto, T. \& Rifkin. D. B. J. Cell Physiol. 151, 81-93 (1992).

18. Kandel, J. et al. Cell 66, 1095-1104 (1991).

19. Sendtner. M., Stöckli, K. A. \& Thoenen. H. J. Cell Biol. 188, 139-148 (1992).

20. Bradley, A. in Teratocarcinomas and Embryonic Stem Cells (ed. Robertson, E. J.) 113-151 (IRL, Oxford. Washington DC. 1987).

21. Capecchi, M. R. Science 244, 1288-1292 (1989).

22. Doetschman, I.. Eistetter. H.. Katz. M., Schmidt, W. \& Kemler, R. J. Embryol. exp. Morphol. 87, 27-85 (1985).

23. Wolf, E., Masu, Y., Thoenen. H. \& Brem. G. Theriogenoiogy 37, 341 (1993). microtrauma that nerves are continuously subjected to by normal mechanical stress could essentially contribute to the latter mechanism. For instance, in rat skin horseradish peroxidase injected into the dermal stroma penetrates into epidermal epithelial cells in consequence of physical activity, resulting in transient membrane wounding permitting the penetration of this molecule, which is larger than $\mathrm{CNTF}^{30}$. In either case, the quantities of CNTF required by the responsive neurons need to be only extremely small.

Other possible physiological functions of CNTF are expected to become apparent during postnatal development only, although many in vitro effects have been observed in embryonic tissues. In vitro effects of CNTF may be accomplished in vivo by other mechanisms and may gain relative importance when the expression of CNTF is abolished. This seems to be the case for the induction of cholinergic properties in adrenergic sympathetic neurons by CNTF, which are characterized by an increase in ChAT and vasoactive intestinal peptide (VIP) levels and a reduction in $\mathrm{TH}^{6.31}$. In preliminary experiments (data not shown), we compared the innervation of sweat glands of CNTF $+/+$ and CNTF $-/-$ mice using immunohistochemical methods and could not find any difference in VIP positive nerve fibres innervating these structures within the footpads. Also ChAT levels of the footpad extracts were not altered in CNTF $-/$ - mice. If CNTF plays a role as a cholinergic differentiation factor, it is certainly not the only molecule responsible for the induction of cholinergic properties in sympathetic neurons innervating the sweat glands. Leukaemia inhibitory factor (LIF) null mutant mice also showed a normal VIP innervation of the sweat glands in the footpads ${ }^{32}$. Besides a broad spectrum of action on the haematopoetic and lymphatic system, LIF has similar effects as CNTF on cultured sympathetic neurons increasing ChAT and reducing $\mathrm{TH}$ activity. It will be of interest to see whether crossbreeding of LIF and CNTF null mutants (experiments that are in progress) will abolish the transformation of sympathetic adrenergic neurons into cholinergic ones by the sweat glands or whether in vivo additional, not yet identified, molecules are responsible for the changes in the properties of sympathetic neurons.

In conclusion, the elimination of the CNTF gene by homologous recombination has demonstrated that the expression of this gene is not necessary for the development of spinal motor neurons as assessed by morphological criteria. But this approach has also shown that CNTF has an essential maintenance function for motor neurons in the postnatal period. To determine other potential physiological functions of CNTF, we expect that similar, very detailed analyses will be necessary to identify subtle, gradually appearing changes in the postnatal phase.

24. Streit, J. W. J. Histochem. Cytochem. 38, 1683-1686 (1990)

25. Streit, J. W., Graeber, M. B. \& Kreutzber, G. W. Glia 1, 301-307 (1988)

26. Tetzlaff, W., Graeber, M. B., Bisby, M. A. \& Kreutzberg, G. Glia 1, 90-95 (1988)

27. Cork, L. C. et al. Lab. Invest. 61, 69-76 (1989).

27. Cork, L. C. et al. Lab. Invest. 61, 69-76 (1989).
28. Munsat, T. L., Andres, P. L., Finison, L., Conlon, T. \& Thibodeau, L. Neurology 38, 409-413 (1988).

29. Meyer, M., Matsuoka, I., Wetmore, C., Olsen, L. \& Thoenen, H. J. Cell Biol. 119, 45-54 (1992)

30. McNeil, P. L. \& Ito. S. J. Cell Sci. 96, 549-556 (1990)

31. Rao. M. S., Patterson, P. H. \& Landis. S. C. Development 116, 731-744 (1992).

32. Rao. M. S. \& Landis, S. C. J. Neurobiol. 24, 215-232 (1993).

33. Abercrombie, M. Anat. Rec. 54, 239-247 (1946).

34. Meyer, O. A., Tilson, H. A., Byrd, W. C. \& Riley, M. T. Neurobehav. Toxicol. 1, 233-236 (1973).

35. SAS/STAT User's Guide Version 6 4th edn. Vol. 2, 891-996 (SAS Institute Inc., Cary, NC. 1989).

36. Ramirez-Solis, R. et al. Analyt. Biochem. 201, 331-335 (1992).

37. Sabatini, D. R., Bensch, K. \& Barnett, R. J. J. Cell Biol. 7, 19-58 (1963).

38. Luft, J. H. J. biophys. biochem. Cytol. 9, $409-414$ (1961).

ACKNOWLEDGEMENTS. We thank R. Kemler for D3 embryonic stem cells. A. Kücherer-Ehret for her contribution in establishing stem cell cultures in the initial phase R. Böhm-Matthaei for introducing the karyotyping of embryonic stem cells, G. W. Kreutzberg for his support of the morphological analysis, D. Bühringer, T. Holy, A. Kussmaul, I. Milojevic. H. Wilde-Launert and H. Heimann for excellent technical assistance, Regeneron Pharmaceuticals. Tarrytown, NY, for recombinant CNTF. I. Hughes, P. Carroll and Y. A. Barde for reading the manuscript and I. Hajar for linguistic and secretarial he!p. 